\title{
OP62
}

\section{LED STREET LIGHTING AND LIGHT POLLUTION- A CASE STUDY IN SOUTH EAST AUSTRALIA

\author{
Mike Chapman
}

DOI 10.25039/x46.2019.OP62

from

CIE x046:2019

\author{
Proceedings \\ of the \\ 29th CIE SESSION \\ Washington D.C., USA, June 14 - 22, 2019 \\ (DOI 10.25039/x46.2019)
}

The paper has been presented at the 29th CIE Session, Washington D.C., USA, June 14-22, 2019. It has not been peer-reviewed by $\mathrm{CIE}$.

(C) CIE 2019

All rights reserved. Unless otherwise specified, no part of this publication may be reproduced or utilized in any form or by any means, electronic or mechanical, including photocopying and microfilm, without permission in writing from CIE Central Bureau at the address below. Any mention of organizations or products does not imply endorsement by the CIE.

This paper is made available open access for individual use. However, in all other cases all rights are reserved unless explicit permission is sought from and given by the CIE.

CIE Central Bureau

Babenbergerstrasse 9

A-1010 Vienna

Austria

Tel.: +4317143187

e-mail: ciecb@cie.co.at

www.cie.co.at 


\title{
LED STREET LIGHTING AND LIGHT POLLUTION - A CASE STUDY IN SOUTH EAST AUSTRALIA
}

\author{
Mike Chapman ${ }^{1}$ \\ ${ }^{1}$ Sydney Outdoor Lighting Improvement Society, Sydney, AUSTRALIA \\ Mike.Chapman@solis.asn.au
}

DOI $10.25039 / \times 46.2019 .0 P 62$

\begin{abstract}
Benefits of LED street lighting have encouraged programs to reduce greenhouse emissions, lighting costs and skyglow. No standardized methods for quantitative assessment of skyglow and light pollution exist. The result of a time series analysis of data from the Suomi/VIIRS satellite from South-East Australia where LED street lights replaced mercury vapour and compact fluorescent lighting is presented here. The total luminous flux of the prior lighting inventory is compared to the radiance images from Suomi Day/Night Band (DNB) and to the expected results from sky-glow modeling software Illumina. Discussion focuses on the Suomi/DNB sensor as a detector and estimator of light pollution. A simplified model of light in the atmosphere suggests short wavelength spectral component of the LED luminaires remains in the lower atmosphere with a greater component of blue spectrum than the original lighting inventory is produced in the wavelengths specified by the AMA as blue light hazard.
\end{abstract}

Keywords: e.g. LED, Sky Glow, Light Pollution, Suomi, VIIRS, blue light hazard, street light

\section{Light as a pollutant}

Where light occurring either naturally or generated by electrical means is excessive or prevents a natural process occurring or detracts from the ability of a task or function to be performed then the level of illumination is too high and the excess level of illumination is considered as a pollutant. In the built environment the following aspects of lighting can be considered as factors in light pollution: obtrusive light, light trespass, glare(discomfort, disability, veiling), clutter and urban sky-glow. A number of definitions [17] of light pollution are in use, here light pollution or artificial light at night (ALAN) is a combination of scattered light, direct light and glare, produced specifically by luminaires. A typical incident of light pollution is where these three factors in combination or singularly interfere with visual observation of a particular object. In visual astronomy light pollution is acknowledged as down grading performance of optical instruments and eyesight, more recently light pollution is acknowledged in the biosphere in forms that interfere with ecological systems of humans, animals and plants.

The direct interference of light the principal forms of scattering are Mie and Rayleigh scattering, Mie scattering occurs where light is incident upon particles (aerosols) of a size larger than the wavelength of the incident light where the scattered light is mainly scattered forwards from the light source and Rayliegh scattering where the particle size (molecules) is smaller than the wavelength of the incident light and the light is scattered randomly including in a backward direction from the source of light.

To a ground based observer the light pollution model can be represented in a simple diagram as seen in Fig. 5. To the observer based on the ground light is incident upon themselves as a combination of Mie Scattering from above and the sides as well as some Rayleigh scattering from the side as well as some direct light received as glare. A component of the light leaves Earth as Rayleigh scattering, whilst it might be possible for some light to leave the Earth on direct path, it is extremely unlikely. The component of light leaving Earth as Rayleigh scattering is the light detected by the sensors on board the Suomi satellite. There is a lack of consensus on the interpretation and definition of light pollution, however for the purposes of this paper and as a general definition light pollution is excessive use of light for the purpose of illumination. This includes light that directly illuminates a field of view as well as light reflected from objects within and away from the field of view. 

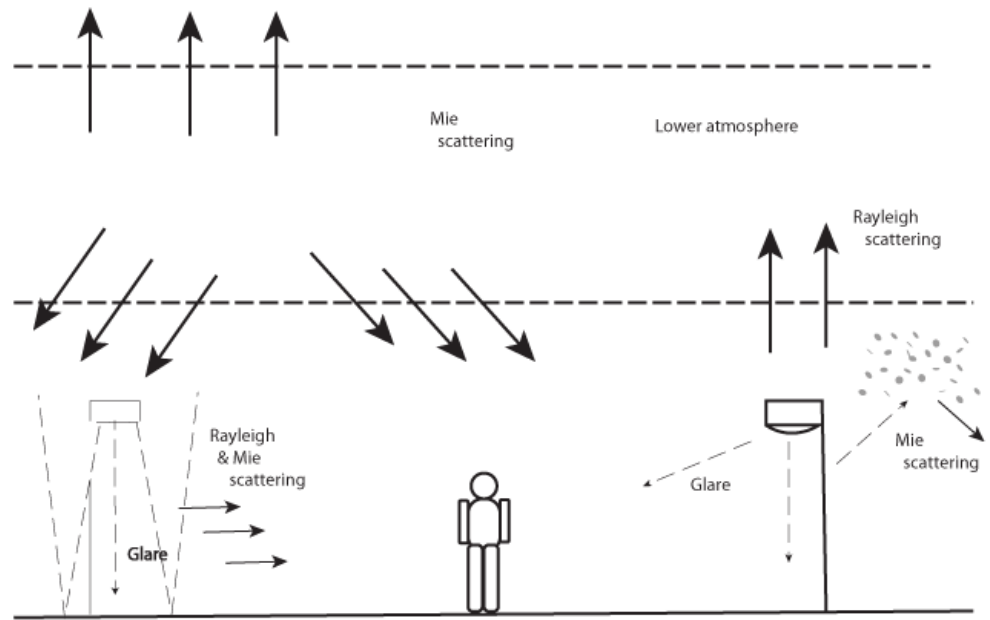

Figure 5 - Scattering of light in the atmosphere.

\subsection{Light in the atmosphere}

A simple model of light in the atmosphere is proposed in Eqn. 1. It is proposed that light from luminaires such as street lighting enters the atmosphere and is then immediately either refracted or reflected in the atmosphere or travels to the ground or a surface where it is reflected. A portion of this light ultimately leaves the Earth where a portion of that light can be detected by sensors on board satellites, such as the Suomi satellite and the remaining quantity of light remains within the atmosphere of the Earth, where some becomes useful illumination and some, in excess of the illumination would be described as light pollution

$$
T_{L E}=R_{O S}+L_{O}+L_{D}+M_{A}+M_{S}+R_{S}
$$

$T_{L E}$ Total luminous flux emitted by luminaire inventory.

Ros Rayleigh scattering emitted to outer space.

Los Light incident on illuminated object.

$L_{D}$ Light incident on the observer.

MA Mie scattering from above.

Ms Mie scattering from the side.

$R s$ Rayleigh scattering from the side.

\section{Case study: Bendigo Victoria}

The town selected for the study is in regional Victoria, Australia, where the LED street light program has completed. The town of particular interest is Bendigo, Victoria and a comparison of the Suomi/VIIRS DNB data as seen in Fig. 1(A) can be seen to closely outline the daytime satellite image from Google Maps in Fig. 1(B). 


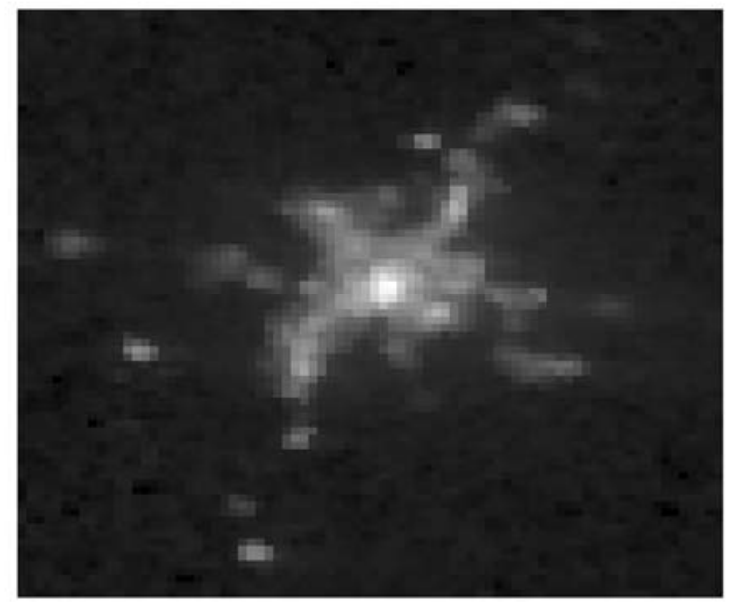

(A) Suomi/VIIRS DNB Bendigo

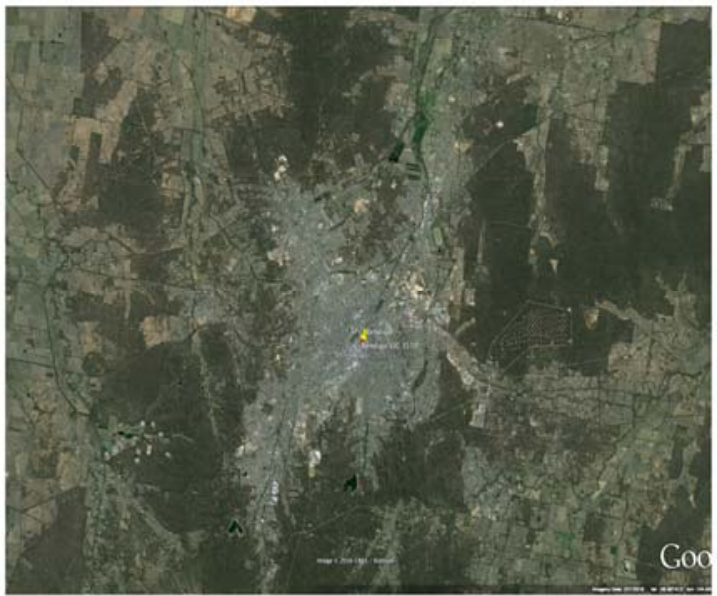

(B) Google Maps: Bendigo

Figure 1 - Comparison of Suomi/VIIRS DNB band image to Google Maps satellite image images not to scale. Night lights are used as indicator of human activity and can be seen as congruent with population distribution.

The comparison images of the LED street light program for Bendigo can be seen in Fig.2, these images were sourced from a third party as a anecdotal attempt to comparison of the affect of the luminaire change on light pollution. This comparison shows a remarkable difference in the light dome over the township. This result is a known aspect of some LED street light programs in other locations around the world as well as Australia. Whilst the
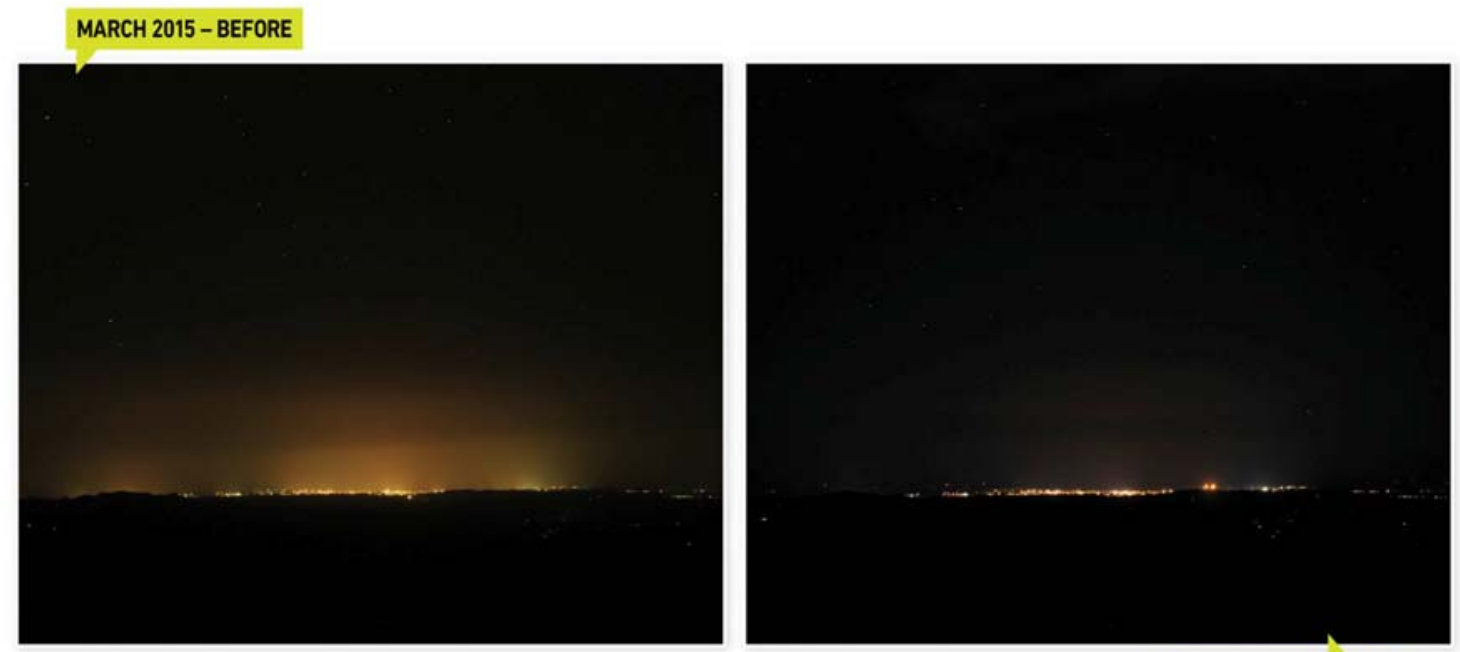

AUGUST 2015 - AFTER

Figure 2 - Bendigo before/after LED street light program. The August 2015 after image shows a distinct reduction in sky-glow. The two distinct aspects of these comparison images is the reduction in the size of the sky glow dome and the change in colour from red/orange to white.

technical details of the photographs is not always known it is acknowledged that the locations and the camera technical settings are appropriate. However some aspects of light need to be taken into consideration to accept if the photos are equivalent in photometric terms other than the physical settings on the camera in use. The primary aspect is that of spectrum and the wavelength of light being detected is strictly dependent on the spectral response of the camera, the lenses in use and the conditions of the atmosphere. A relatively simple split of the colour images into the red, green and blue channels. In Fig. 3 the blue channel has been 
separated and it shows that the light dome has decreased in lateral extent but still exists in elevation.
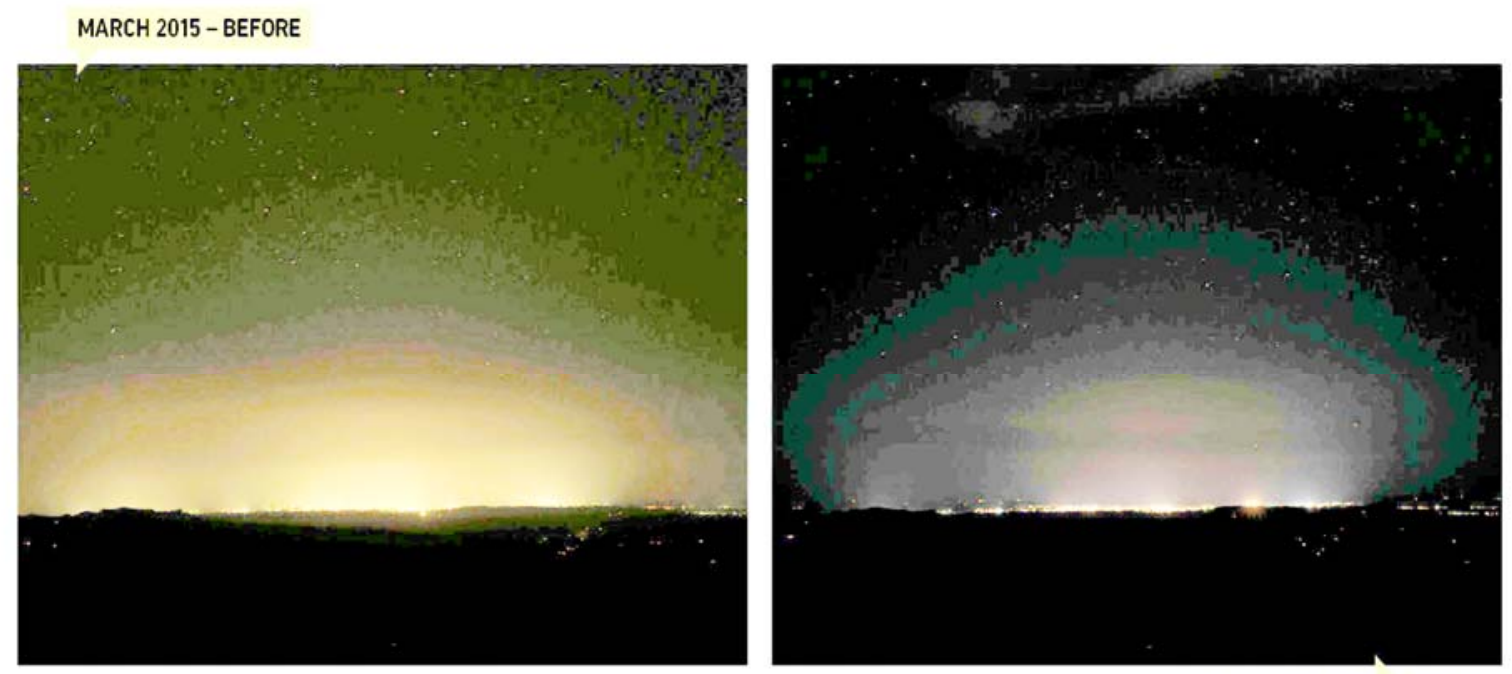

AUGUST 2015 - AFTER

Figure 3 - Bendigo before/after LED street light program - blue channel.When examining the blue channel only. The reduction in light dome is still evident. The light dome is still apparent and obvious.

Table 1 - Bendigo: Original lighting technology.

\begin{tabular}{|l|l|l|l|l|l|}
\hline \multicolumn{1}{|c|}{ Luminaire } & Wattage & Total installed & $\begin{array}{l}\text { Luminaire } \\
\text { lumens }\end{array}$ & $\begin{array}{l}\text { Total } \\
\text { lumens }\end{array}$ & $\%$ cont. \\
\hline GS114ME4 & 14W & 17 & 1,066 & 18,122 & 0.1 \\
\hline Eco CFL 26W & 24W & 2 & 1,056 & 2,112 & 0.0 \\
\hline Eco CFL 32W & $32 \mathrm{~W}$ & 79 & 1,809 & 142,911 & 0.7 \\
\hline Eco CFL 42W & $42 \mathrm{~W}$ & 745 & 2,334 & $1,738,830$ & 8.4 \\
\hline M50D & $50 \mathrm{~W}$ & 2 & 1,524 & 3,048 & 0.0 \\
\hline M80D & $80 \mathrm{~W}$ & 6,127 & 3,046 & $18,662,842$ & 90.1 \\
\hline M125D & $125 \mathrm{~W}$ & 29 & 4,897 & 142,013 & 0.7 \\
\hline
\end{tabular}

From Table 1. the total luminous flux of the lighting inventory can be calculated based on supplied datasheets. The replacement LED luminaire being a Sylvania Street LED 18W with a luminous flux based on the luminaire of $2105 \mathrm{Im}$. The total luminous flux emitted by the installed luminaire base in Bendigo prior to the change to LED is $20,709,878 \mathrm{Im}$. The majority of luminaires are either of the type M80D or Eco CFL 42W. Here, only the major component luminaires are to be considered, see Table 2. The results of the luminaire conversion shown in Table 3 demonstrate a significant decrease in total luminous flux from $20,709,878$ to $15,368,605$ lumens, a decrease of $25.8 \%$. 
Table 2 - Bendigo: Total luminous flux (post change) The replacement luminaire was of only a single type, StreetLED $18 \mathrm{~W}$.

\begin{tabular}{|c|l|l|l|}
\hline Luminaire & Total installed & $\begin{array}{l}\text { Luminaire } \\
\text { lumens }\end{array}$ & $\begin{array}{l}\text { Total } \\
\text { lumens }\end{array}$ \\
\hline StreetLED 18W & 7301 & 2105 & 15368605 \\
\hline
\end{tabular}

Table 3 - Bendigo: Comparison of luminous flux. The comparison of prior/post luminous flux shows a significant $25.8 \%$ decrease.

\begin{tabular}{|l|l|}
\hline \multicolumn{1}{|c|}{ Phase } & $\begin{array}{l}\text { Total } \\
\text { luminous } \\
\text { flux (lumens) }\end{array}$ \\
\hline Prior & $20,709,878$ \\
\hline Post & $15,368,605$ \\
\hline
\end{tabular}

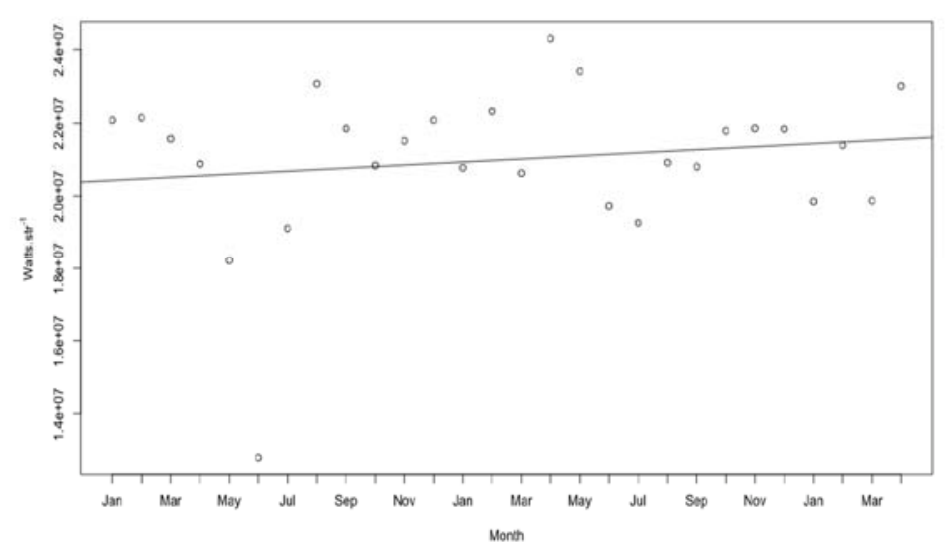

Figure 4 - Suomi/VIIRS - DNB Bendigo 2014 - 2016. This figure shows the total radiant intensity from January 2014 to April 2016. The period post April 2015 displays an overall lower level of radiosity

The Suomi/VIIRS DNB data can be presented in relation to a model of a form represented by Duriscoe et. al. Rather than look at a single point in time as done by Duriscoe, here in Fig. 4 the DNB data is presented as a time series. The time series plot for Bendigo over 2014-2016 in Fig. 4 shows significant variation in total radiance, the low values across May-July 2014 in particular. However the period of the LED replacement program May to July 2015 shows a drop and increase in radiance followed by a stable period of 3 months. It is suggested that the period of the change over would be expected to be unstable and also that the completion of the program would see a stable period.

\subsection{Spectral analysis}

The spectral nature of the generated light is of significant concern when considering the ecological and astronomical impacts on the environment. The primary concern is the spectral component in the blue wavelength. It should be noted that other wavelengths also have an impact on specific behaviours in ecosystems, vegetation is impacted in the red spectrum. Here the chosen wavelength range for blue extends from $380 \mathrm{~nm}$ to $500 \mathrm{~nm}$, additionally this band has been split to show the ranges for $380 \mathrm{~nm}-450 \mathrm{~nm}$ and $450 \mathrm{~nm}-500 \mathrm{~nm}$, the wavelength range $450 \mathrm{~nm}-500 \mathrm{~nm}$ is inclusive of the range cited by the AMA as the strongest range influencing melatonin suppression. 
Table 4 - Bendigo: \% blue component in spectrum. The wavelength band $380 \mathrm{~nm}-500 \mathrm{~m}$ is a general indicator of visual blue for humans, the wavelength band $450 \mathrm{~nm}-500 \mathrm{~nm}$ is cited by the American Medical Association as the strongest wavelengths causing suppression of melatonin

\begin{tabular}{|l|l|l|l|l|}
\hline \multicolumn{1}{|c|}{ Luminaire } & Wattage & $380 \mathrm{~nm}-500 \mathrm{~nm}$ & $380 \mathrm{~nm}-450 \mathrm{~nm}$ & $450 \mathrm{~nm}-500 \mathrm{~nm}$ \\
\hline StreetLED & 18 & 17.6 & 8.2 & 9.4 \\
\hline M125D & 125 & 18.4 & 17.0 & 1.4 \\
\hline M80D & 80 & 28.0 & 25.7 & 2.3 \\
\hline Eco CFL 42 & 42 & 28.7 & 21.8 & 6.9 \\
\hline Eco CFL 32 & 32 & 27.4 & 19.7 & 7.7 \\
\hline
\end{tabular}

Table 5 - Bendigo:Total Luminous Power blue - $380 \mathrm{~nm}-500 \mathrm{~nm}$. The total watts in the blue spectrum $380 \mathrm{~nm}-500 \mathrm{~nm}$ shows a reduction of $85 \%$ from 147,608 Watts to 22,182 Watts.

\begin{tabular}{|l|l|l|l|l|l|}
\hline \multicolumn{1}{|c|}{ Luminaire } & Wattage & $\begin{array}{c}380 \mathrm{~nm}-500 \mathrm{~nm} \\
\% \text { of spectrum }\end{array}$ & $\begin{array}{l}\text { Power } \\
\text { Watts }\end{array}$ & Total Installed & $\begin{array}{c}\text { Total Watts } \\
380 \\
\mathrm{~nm}\end{array}$ \\
\hline StreetLED & 18 & 17.6 & 3 & 7,001 & 22,182 \\
\hline M125D & 125 & 18.4 & 23 & 30 & 690 \\
\hline M80D & 80 & 28.0 & 22 & 6,127 & 137,245 \\
\hline Eco CFL 42 & 42 & 28.7 & 12 & 745 & 8,980 \\
\hline Eco CFL 32 & 32 & 27.4 & 8 & 79 & 693 \\
\hline
\end{tabular}

Table 6 - Bendigo:Total Luminous Power 450 nm - 500 nm Melatonin suppression. In the wavelength range specified by the AMA for the suppression of melatonin the reduction in power is 13,681 watts to 11,847 watts a decrease of $13.4 \%$

\begin{tabular}{|l|l|l|l|l|l|}
\hline \multicolumn{1}{|c|}{ Luminaire } & Wattage & $\begin{array}{c}450 \mathrm{~nm}-500 \mathrm{~nm} \\
\% \text { of spectrum }\end{array}$ & $\begin{array}{l}\text { Power } \\
\text { Watts }\end{array}$ & Total Installed & $\begin{array}{c}\text { Total Watts } \\
\mathrm{nm}-500 \\
\mathrm{~nm}\end{array}$ \\
\hline StreetLED & 18 & 9.4 & 1.69 & 7,001 & 11,847 \\
\hline M125D & 125 & 1.4 & 1.75 & 30 & 53 \\
\hline M80D & 80 & 2.3 & 1.84 & 6,127 & 11,274 \\
\hline Eco CFL 42 & 42 & 6.9 & 2.89 & 745 & 2,159 \\
\hline Eco CFL 32 & 32 & 7.7 & 2.46 & 79 & 195 \\
\hline
\end{tabular}

In Table 5 the total power in the blue spectrum $(380 \mathrm{~nm}-500 \mathrm{~nm})$ for each major luminaire in use in Bendigo can be compared to the StreetLED. The total luminous power has reduced from $147,608 \mathrm{~W}$ to $22,182 \mathrm{~W}$. In Table 6 the total power in the wavelength band $450 \mathrm{~nm}-500$ $\mathrm{nm}$ where suppression of melatonin is most significant the reduction in power from $13,681 \mathrm{~W}$ to $11,847 \mathrm{~W}$, a reduction of approximately $13.4 \%$.

Table 7 - Bendigo:Total luminous intensity blue spectrum. In the wavelength range specified by the AMA the total luminosity for the StreetLED $18 \mathrm{~W}$ is $104,184 \mathrm{Im}$ compared to a total of $14,504 \mathrm{Im}$ for the original inventory.

\begin{tabular}{|l|l|l|l|l|l|}
\hline \multicolumn{1}{|c|}{ Luminaire } & \multicolumn{1}{|c|}{$\begin{array}{c}\text { Luminaire } \\
\text { Lumens }\end{array}$} & $\begin{array}{c}380 \mathrm{~nm}-500 \mathrm{~nm} \\
\% \text { of spectrum }\end{array}$ & $\begin{array}{c}450 \mathrm{~nm}-500 \mathrm{~nm} \\
\% \text { of spectrum }\end{array}$ & $\begin{array}{c}\text { Total Lumens } \\
380 \mathrm{~nm}-500 \mathrm{~nm}\end{array}$ & $\begin{array}{c}\text { Total Lumens } \\
450 \mathrm{~nm}-500 \mathrm{~nm}\end{array}$ \\
\hline StreetLED & 2105 & 17.6 & 9.4 & $7,587,402$ & 104,184 \\
\hline M125D & 4897 & 18.4 & 1.4 & 27,031 & 53 \\
\hline M80D & 3046 & 28.0 & 2.3 & $5,481,460$ & 11,826 \\
\hline Eco CFL 42 & 2334 & 28.7 & 6.9 & 499,044 & 2,406 \\
\hline Eco CFL 32 & 1809 & 27.4 & 7.7 & 39,158 & 219 \\
\hline
\end{tabular}


The AMA targeted wavelength range is included in the range $450 \mathrm{~nm}-500 \mathrm{~nm}$. In Table 7 the StreetLED has a much higher total luminosity than the previous mix of luminaries, a total of $104,184 \mathrm{Im}$ for the StreetLED as compared to the $14,504 \mathrm{Im}$ for the original inventory an increase of $618 \%$.

\subsection{Luminaire spatial analysis}

A significant advantage seen in the development of LED based luminaires is the ability to utilise the high efficacy of the LED and well designed optical components to confine and concentrate the light beam spread to in- crease the ground level illumination. The modelling presented here from AGI32 shows that the LED replacement has resulted in a very similar level of ground illumination compared to the modelling of the two luminaire types replaced. In the case of the Sylvania Street LED 18W these levels were measured in the field at a similar location with an identical luminaire and the level of illumination was 10 to $11 \mathrm{Ix}$, as compared to the modelled value of $6.4 \mathrm{~lx}$.

In Fig. 5 and Fig. 6 the spatial distributions as modelled in AGI32 using the luminaire IES files. The spatial plots are based on a grid spacing of 10 metres separation and shows a similar patter and similar levels of illumination. Here it is important to note the significant difference in luminosity and power of the luminaire whilst a similar level of illumination has been maintained at ground level. The mounting height is 6.5 metres, which is the standard mounting height of Category ' $P$ ' luminaires in most Australian cities and towns.

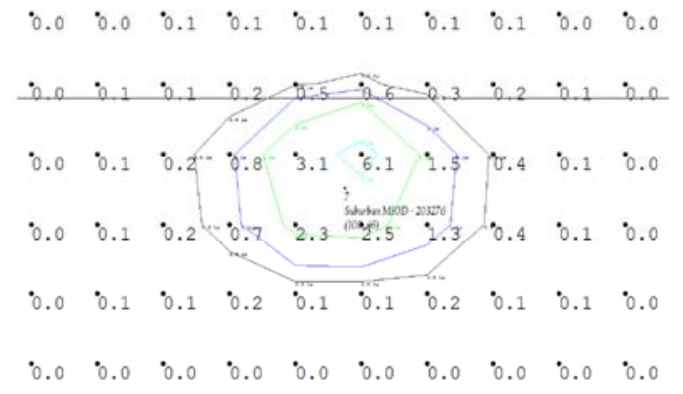

(A) Suburban M80D 80W:

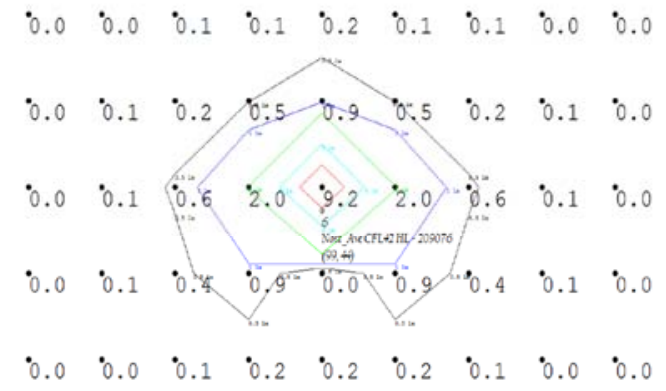

(B) Eco CFL 42W

Figure 5 - Luminaire modeling AGI32: Distribution of light from primary luminaires. Shows illuminance levels in lux at ground level. Grid spacing at 10 metre

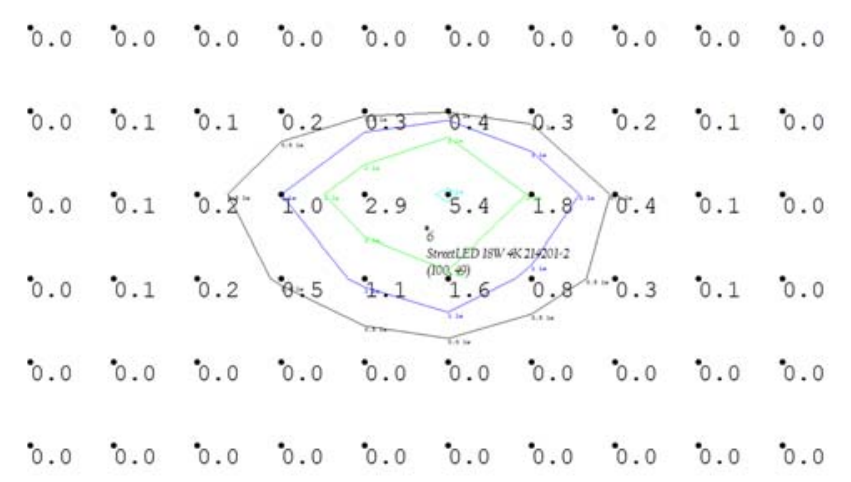

Figure 6 - Luminaire modeling AGI32: Sylvania StreetLED 18w. Shows illuminance levels in lux at ground level. Grid spacing at 10 metres.

\subsection{Illumina model: Bendigo}

The results for the Illumina model of Bendigo the results are displayed in Fig.7 and Fig. 8, the trend for the total radiance for the bands $420 \mathrm{~nm}, 500 \mathrm{~nm}, 580 \mathrm{~nm}, 660 \mathrm{~nm}$ showing an expected decrease in radiance values. The Illumina model uses a modelled radius of $12 \mathrm{~km}$. 


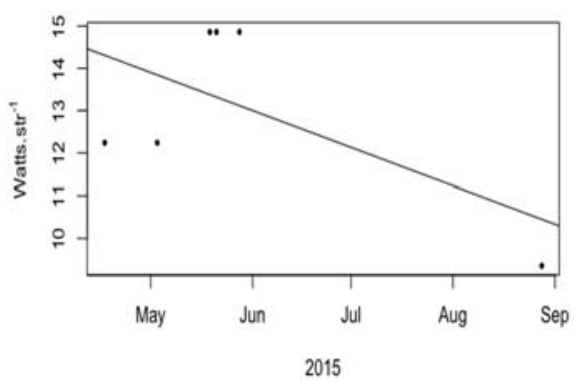

(A) Bendigo 2015: Total radiance $420 \mathrm{~nm}$

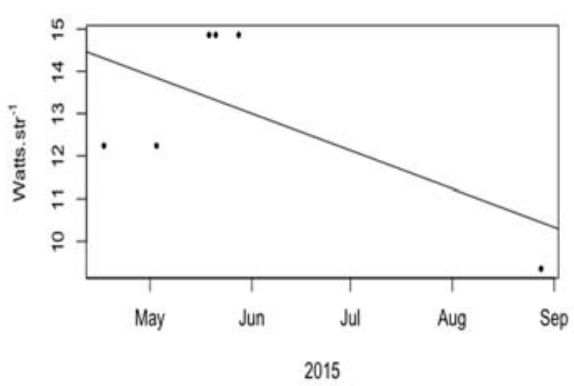

(B) Bendigo 2015: Total radiance $500 \mathrm{~nm}$

Figure 7 - Bendigo Total Radiance 2015 - Illumina modeling. The modeling result from Illumina show an expected significant decrease in total radiosity from using the StreetLED luminaires.

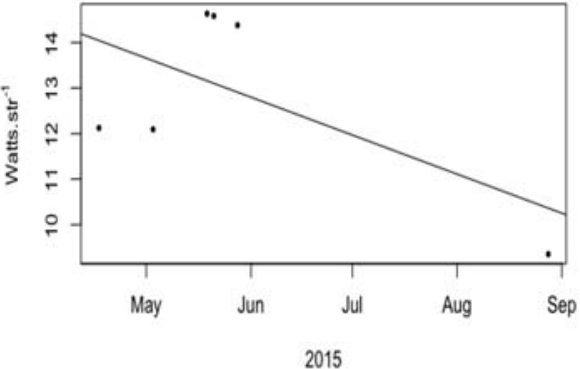

(A) Bendigo 2015: Total radiance $420 \mathrm{~nm}$

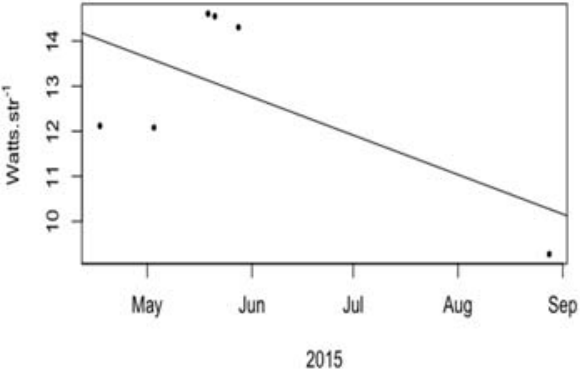

(B) Bendigo 2015: Total radiance $500 \mathrm{~nm}$

Figure 8 - Bendigo Total Radiance 2015 - Illumina modelling. The modelling results from Illumina longer wavelengths also show an expected significant decrease in radiosity when StreetLED luminaires are installed.

\subsection{Bendigo spatial analysis}
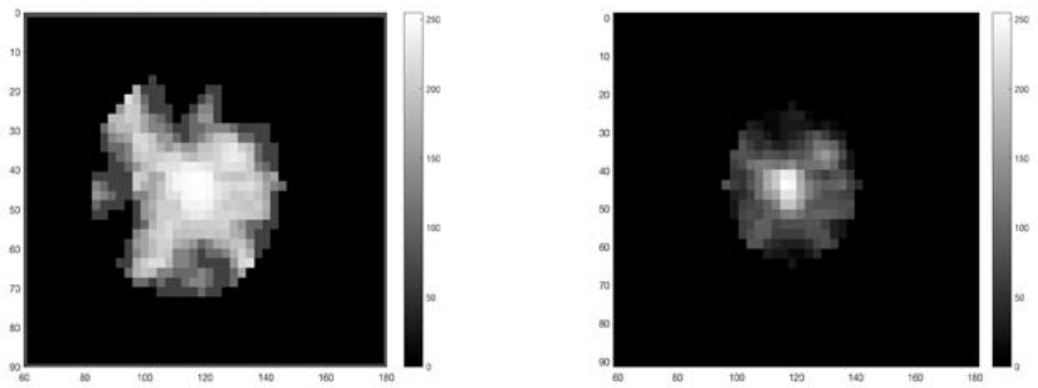

Figure 9 - Bendigo Total Radiance 2015 - Illumina modelling. The modelling results from Illumina longer wavelengths also show an expected significant decrease in radiosity when StreetLED luminaires are installed

The areal extent of the Bendigo area can be further investigated by looking at the statistics for the maximum and minimum values and the areal extent. Here in Fig.9 it is seen that the StreetLEDs have intensified in location and the areas where there is a likely lower density of luminaires the radiance has dropped. 
Table 8 - Bendigo: Total luminous intensity blue spectrum. In the wavelength range specified by the AMA the total luminosity for the StreetLED $18 \mathrm{~W}$ is $104,184 \mathrm{Im}$ compared to a total of $14,504 \mathrm{Im}$ for the original inventory.

\begin{tabular}{|l|l|l|l|l|}
\hline \multicolumn{1}{|c|}{ Day } & Total & Average & Minimum & Pixels (non-zero) \\
\hline 92 & 2443389 & 6430 & 809 & 380 \\
\hline 254 & 1799476 & 9181 & 910 & 196 \\
\hline
\end{tabular}

The results of the Illumina model shown in Figs. 12(A) and 12(B) and Table 8 show the modelled results of the original lighting inventory at Day 92 of 2015 and at completion at Day 254 of 2015 for the wavelength $420 \mathrm{~nm}$. The reduction in power and luminosity of the StreetLED is evident in the reduction and extent of the outlying areas from the central point and this is confirmed by the count of non-zero pixels dropping from the prior position of 380 pixels to 196 pixels at the end of the refit program

\section{Discussion}

The results show that the Suomi VIIRS/DNB data can be used to register ground level changes in illumination. However a number of physical and geographic factors contribute to altering the signal value on a time based scale. Some of the large variations in total radiance demonstrated in the case study of Bendigo, Victoria cannot be simply attributed without ground based time series data to assist correlation the variations are assumed to be attributed to local weather conditions. As a result of other studies it is known that factors such as albedo and atmospheric transparency moderate the signal received by the Suomi satellite.

\subsection{Bendigo}

The VIIRS/DNB data for the town of Bendigo can be seen to have a strong geographical match to the actual physical town. The town has a strongly lit centre with ribbon arms into suburban districts. The total power in the blue spectrum $380 \mathrm{~nm}-500 \mathrm{~nm}$ of the original lighting inventory of $147,608 \mathrm{~W}$ decreased to $22,182 \mathrm{Wa}$ decrease of $85 \%$ and the decrease in total luminous flux is $25.8 \%, 20,709,878 \mathrm{Im}$ to $15,368,605 \mathrm{Im}$. The results of the modeling in Illumina shown in show an expected increase in the level of illumination across all modeled wavelengths. Additionally, the modeled coverage shows a significant reduction in areal coverage and a likely explanation for the reduced skyglow seen in the before/after comparison images for Bendigo is that the reduced total luminous flux is now mostly concentrated within the town centre.

\subsection{AMA blue light hazard}

The wavelength range selected to represent the AMA specified range of $446 \mathrm{~nm}$ to $477 \mathrm{~nm}$ is $450 \mathrm{~nm}$ to $500 \mathrm{~nm}$. Within this range it was found that the component of the spectrum in the original luminaire inventory for the AMA defined range was $14,504 \mathrm{Im}$ and the total for the replacement StreetLED is $104,184 \mathrm{Im}$ an increase of $618 \%$. When considering the wider blue wavelength range of $380 \mathrm{~nm}$ to $500 \mathrm{~nm}$ the change from the prior lighting inventory was $6,046,693 \mathrm{Im}$ to $7,587,402 \mathrm{Im}$ an increase of $25.5 \%$. The significant decrease in the total luminous flux has not led to a significant decrease in blue spectrum and in particular the blue component in the AMA specified range has increased significantly.

\section{Conclusion}

The analysis shows that in the case of Bendigo the street light program to replace the original technology with all LED luminaires has resulted in an overall reduction total radiance and a consequent reduction in skyglow appears to be supported by the comparison images for Bendigo. Some interesting aspects that can be seen are the significant reductions in blue spectrum and the significant proportion of blue spectrum that existed in the original lighting inventory. In other locations where this change to LED technology has occurred there has been a public response to change the luminaire technology to a lower correlated colour temperature (CCT). This appears to be contradictory to the results presented here, in consideration of some limitations, not all aspects of the model may be exact. The known limitations are: the luminaire specifications used here are based on estimations of an installed base that would have been used, based on market knowledge, the Council databases are not 
luminaire model specific. There is no allowance for maintenance factor for either the original luminaire inventory or for the replacement StreetLED, it must be noted that the original lighting may be at or beyond their useful life span and likely to be underperforming. The luminaires changed over are known as Category ' $P$ ', this is a type for suburban roads intended for pedestrians, the existing luminaires for vehicular traffic on arterial roads Category 'V' have not been converted LED technology.

Any future study would benefit from ground data collected on the basis of before/after conversion, this data would be of the form of zenithal dark-sky estimates using integrating photo-detectors such as 'Sky Quality Meters' (SQM) 1. As well as low altitude night time photography as used in the study by Kuechely et. al. There also needs to be further study on collecting comparison images, such as the images used here for Bendigo and defining a strict technical baseline for the comparison of these images across specified and targeted wavelengths.

\section{References}

JARI LYYTIMAKI and JANNE RINNE 2013. Voices for the darkness: online survey on public perceptions on light pollution as an environmental problem. Journal of Integrative Environmental Sciences, 10(2):127-139

DURISCOE D.M. et al. 2014, The relation of outdoor lighting characteristics to sky glow from distant cities. Lighting Research \& Technology, 46(1):35-49.

Unihedron. 2017, http://www.unihedron.com/.

LEDS Magazine, 2015,

http://www.ledsmagazine.com/articles/print/volume-12/issue-10/features/street-lights/lightpollution-depends-on-thelight-source-cct.html.

KUECHLY HELGA U., et. al., 2012, Aerial survey and spatial analysis of sources of light pollution in Berlin, Germany. Remote Sensing of Environment, 126:39-50, 2012.

\section{Acknowledgements}

The author wishes to acknowledge the assistance of the following people:

Associate Professor Dr Wendy Davis: Sydney University, New South Wales, Australia: Supervisor Masters project.

Professor Dr Martin Aube: Sherbrooke University, Ottawa, Canada, assistance with Illumina.

Dan Duriscoe: US National Park Service, assistance on interpreting VIIRS/ DNB data

Dr Changyong Cao: Post doctoral researcher NOAA, assistance on interpreting VIIRS/DNB data.

Dr Inakwu Odeh: Lecturer University of Sydney, advice on GIS and remote sensing,

Andy Nagy : Gerard Lighting, Application Manager Road \& Infrastructure, provided spectral data and IES files.

Andrea Joyce: Contract project manager for LED street lighting program Bendigo Council. Provided Bendigo lighting database and Bendigo comparison image. 